\title{
Preference classes in society for coastal marine protected areas
}

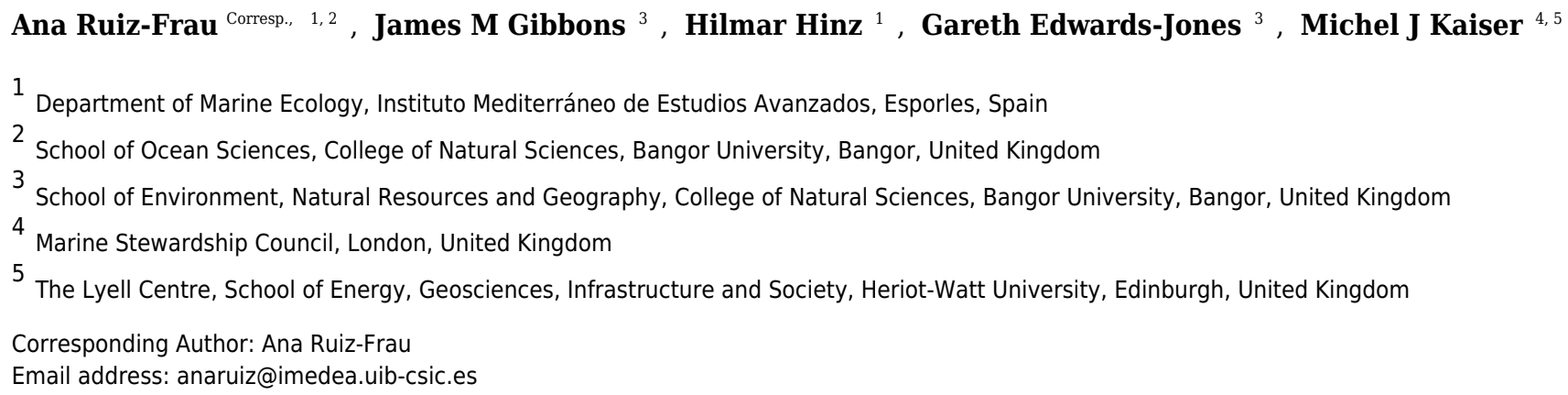

Marine protected areas (MPAs) are increasingly being used as conservation tools in the marine environment. Success of MPAs depends upon sound scientific design and societal support. Studies that have assessed societal preferences for temperate MPAs have generally done it without considering the existence of discrete groups of opinion within society and have largely considered offshore and deep-sea areas. This study quantifies societal preferences and economic support for coastal MPAs in Wales (UK) and assesses the presence of distinct groups of preference for MPA management, through a latent class choice experiment approach. Results show a general support for the protection of the marine environment in the form of MPAs and that society is willing to bear the costs derived from conservation. Despite a general opposition towards MPAs where human activities are completely excluded, there is some indication that three classes of preferences within society can be established regarding the management of potentially sea-floor damaging activities. This type of approach allows for the distinction between those respondents with positive preferences for particular types of management from those who experience disutility. We conclude that insights from these types of analyses can be used by policy-makers to identify those MPA designs and management combinations most likely to be supported by particular sectors of society. 


\section{Preference classes in society for coastal marine protected areas}

2 Ana Ruiz-FrauCorresp., 1, 2 , James M. Gibbons ${ }^{3}$, Hilmar Hinz ${ }^{1}$, Gareth Edwards-Jones ${ }^{3}$, Michel J

3 Kaiser ${ }^{4,5}$

$4{ }^{1}$ Department of Marine Ecology, Instituto Mediterraneo de Estudios Avanzados, Esporles, 5 Spain.

$6{ }^{2}$ School of Ocean Sciences, College of Natural Sciences, Bangor University, Bangor, UK

$7{ }^{3}$ School of Environment, Natural Resources and Geography, College of Natural Sciences, Bangor

8 University, Bangor, UK

$9 \quad{ }^{4}$ Marine Stewardship Council, London, UK

$10{ }^{5}$ The Lyell Centre, School of Energy, Geosciences, Infrastructure and Society, Heriot-Watt

11 University, Edinburgh, UK

12

13 Corresponding author: Ana Ruiz-Frau

14 Email address: anaruiz@imedea.uib-csic.es

15 
16 ABSTRACT

17 Marine protected areas (MPAs) are increasingly being used as conservation tools in the marine

18 environment. Success of MPAs depends upon sound scientific design and societal support.

19 Studies that have assessed societal preferences for temperate MPAs have generally done it

20 without considering the existence of discrete groups of opinion within society and have largely

21 considered offshore and deep-sea areas. This study quantifies societal preferences and

22 economic support for coastal MPAs in Wales (UK) and assesses the presence of distinct groups

23 of preference for MPA management, through a latent class choice experiment approach.

24 Results show a general support for the protection of the marine environment in the form of

25 MPAs and that society is willing to bear the costs derived from conservation. Despite a general

26 opposition towards MPAs where human activities are completely excluded, there is some

27 indication that three classes of preferences within society can be established regarding the

28 management of potentially sea-floor damaging activities. This type of approach allows for the

29 distinction between those respondents with positive preferences for particular types of

30 management from those who experience disutility. We conclude that insights from these types

31 of analyses can be used by policy-makers to identify those MPA designs and management

32 combinations most likely to be supported by particular sectors of society. 
34 The marine environment provides society with a wide range of goods and services that are 35 essential for the maintenance of our economic and social wellbeing (MEA 2005; Liquete et al.

36 2013; Costanza et al. 2014). The recognition of the effects of anthropogenic activities on marine

37 ecosystems has led to increasing conservation initiatives globally. Marine protected areas

38 (MPAs) are among the most important tools available for achieving global marine conservation

39 targets, which are recognized both at international and European level (OSPAR 2003; CBD 2008;

40 MSFD 2008).

41 Although the role of MPAs in the recovery of fish stocks and fisheries management remains an

42 issue of debate (Kaiser 2005; Stefansson and Rosenberg 2006; Hilborn 2018), it is clear that the

43 establishment of MPAs has positive benefits for habitat restoration and biodiversity

44 conservation within the boundaries of the MPA (Halpern 2003; Blyth-Skyrme et al. 2006).

45 However, the creation and enforcement of MPAs is costly (Balmford et al. 2004) and despite

46 their potential benefits, their designation is often complex both legally and socially. This is

47 because the closure of portions of the sea to human activities has impacts on those sectors of

48 society directly affected by the closures, and not all of these impacts are perceived as positive.

49 However, if designed carefully MPAs can achieve a balance between marine conservation and

50 socio-economic objectives (Klein et al. 2008; Ruiz-Frau et al. 2015a, b). Consequently, the

51 design of MPAs is better addressed from an interdisciplinary perspective that is able to provide

52 insights into the range of potential consequences of implementation. If MPAs are to

53 successfully achieve their conservation objectives, then the biological principles of good reserve 
54 design need to have a strong influence on the designation process (Roberts et al. 2003),

55 unfortunately however this is not always the case (Caveen et al. 2013, 2015). In addition,

56 conservation objectives cannot be met without support from members of local communities,

57 resource users and policy makers (Moore et al. 2004). Through the acknowledgement of the

58 role of the marine environment as supplier of ecosystem services and benefits fundamental for

59 the maintenance of human wellbeing (MEA 2005), there is increasing pressure to engage

60 stakeholders and in general members of society into marine and coastal planning (EU 2001;

61 Epstein et al. 2014; Christie et al. 2017). This paper focuses on expanding current knowledge

62 about how the general public perceives and values the conservation of the marine environment

63 and how distinct opinion groups can be established in society based on MPA management

64 preferences. To do this, a case study using discrete choice experiment methodology to assess

65 society's preferences for the establishment of MPAs around the coast of Wales (UK) is

66 undertaken.

67 Discrete choice experiments (DCEs) are survey-based methodologies where respondents are

68 asked to choose their most preferred alternative among a set of hypothetical alternatives. Each

69 alternative is characterized by the same bundle of attributes, however the alternatives differ in

70 the levels displayed by the attributes. Through the analysis of responses, the marginal rate of

71 substitution between any pair of attributes that differentiate the alternatives can be

72 determined. If one of the attributes has a monetary price attached to it, it is then possible to

73 compute the respondent's willingness to pay (WTP) for the other attributes (Hanley et al. 1998;

74 Liu et al. 2010). 
75 The body of literature using DCEs to determine the economic preferences and value that

76 society attaches to the conservation of the marine environment through MPAs is rapidly

77 growing (Torres and Hanley, 2017). A high proportion of studies however have focused on

78 tropical areas and on coral habitats, which are highly charismatic and might attract higher WTP

79 from the public (e.g. Mwebaze and MacLeod, 2013; Rogers, 2013; Rolfe and Windle, 2012; and

80 references in Torres and Hanley, 2016), however cultural aspects need to be taken into account

81 when considering studies from different locations, as charismatic species are not always the

82 main drivers in the WTP for biodiversity conservation (Ressurreição et al. 2012). Similarly,

83 studies on temperate areas are also increasing albeit at a lower pace (McVittie and Moran

84 2010; Wattage et al. 2011; Börger et al. 2014; Jobstvogt et al. 2014b, a; Kermagoret et al. 2016;

85 Börger and Hattam 2017). In general, these studies indicate that society values and is willing to

86 support the additional economic costs associated to conservation. As an example, Jobstvogt et

87 al. 2014 showed high WTP values ( $£ 70$ to $£ 77$ ) for the protection of deep sea biodiversity while

88 McVittie and Moran 2010 found values of similar magnitude for halting the loss of marine

89 biodiversity in UK waters ( $£ 21$ to $£ 34$ ). However, the focus of the DCE studies on temperate

90 MPAs has largely been on offshore and deep-sea areas (Wattage et al. 2011; Börger et al. 2014;

91 Jobstvogt et al. 2014a; Kermagoret et al. 2016; Börger and Hattam 2017), on the WTP for the

92 protection of charismatic species such as marine mammals through the use of MPAs (Boxall et

93 al. 2012; Batel et al. 2014) or on particular segments of society such as divers (Sorice et al.

94 2009; Jobstvogt et al. 2014b). Additionally, those studies that considered society as a whole did

95 not explore the existence of discrete opinion groups with distinct preferences for the

96 management of MPAs and how this might be linked to particular socio-demographic 
97 characteristics and attitudinal aspects, as suggested by Börger and Hattam (2017) in a study on

98 offshore areas. We argue that this type of information can be highly relevant for policy-makers

99 during an MPA design process in order to enhance societal support.

100 The present study focuses on Wales in the United Kingdom (UK), a region with a long coastline

101 (approximately, $2700 \mathrm{Km}$ ) and strong historic connections to the sea, where Government

102 developed a Marine and Coastal Access Act 2009 in which it commits to "establishing an

103 ecologically coherent, representative and well-managed network of marine protected areas"

104 taking into account "environmental, social and economic criteria" (DEFRA 2009). In Wales,

105 comprehensive information is available for the distribution of biophysical and ecological

106 factors, however information on how much the public values the conservation of the marine

107 environment or on the support for MPAs in the area is scarce.

108 This case study offers an assessment of societal support for coastal MPAs located in temperate

109 areas and analyses the assumption that there is preference heterogeneity in society for the

110 type of protection of the marine environment and that discrete classes of preferences can be

111 established through a DCE. Additionally, the focus of the study is on coastal waters for which

112 people might be more familiar with and might have a greater sense of attachment in

113 comparison to offshore areas and therefore preferences might differ.

115 2. METHODS 
116 The economic value associated with changes in the size and uses allowed within the boundaries

117 of a temperate coastal MPA network were estimated using a discrete choice experiment (DCE).

118 DCE data were collected using questionnaires. Heterogeneity in societal preferences for MPAs

119 was estimated with a latent class choice experiment model (Train 2009).

120 Figure 1 about here

$121 \quad 2.1$ Choice Experiments Econometrics

122 The economic framework for DCE lies in Lancaster's theory of consumer choices (Lancaster

123 1966), which assumes that the utility of a good can be decomposed into the utilities of the

124 characteristics of that good and as a result consumers' decisions are determined by the utility

125 of the attributes rather than by the good itself. The econometric basis for DCE is provided by

126 the random utility theory framework, which describes consumers' choices as utility

127 maximization behaviors. Through the analysis of DCE data, marginal values for the attributes of

128 a good or individual's willingness to pay (WTP) can be calculated (Hensher et al. 2007).

129 However, DCE approaches remain controversial because of their hypothetical nature and the 130 contested reliability of their results (Hausman 2012), although it has been concluded that DCE

131 remains useful for non-market valuation, its results should be used with caution (Rakotonarivo 132 et al. 2016).

133 DCEs can be analyzed using different models. Due to its simplicity, the multinomial logit model

134 (MNL) is the most widely used. This model has important limitations; specifically, it assumes

135 independence of irrelevant alternatives (IIA) and it assumes homogeneous preferences for all

136 respondents (Hausman and McFadden 1984). However, within society preferences are 
137 heterogeneous and the ability to account for this variation allows the estimation of unbiased

138 models that provide a better representation of reality. Random parameter logit models (RPL)

139 and latent class logit models (LC) relax the limitations of standard logit by allowing random

140 taste variation and unrestricted substitution patterns in their estimation. The RPL allows utility

141 parameters to vary randomly across individuals while in the LC formulation preference

142 heterogeneity is captured by simultaneously assigning individuals into latent segments or

143 "classes" while estimating a choice model. Within each latent class, preferences are assumed

144 homogeneous, but these can vary between classes (Boxall and Adamowicz 2002; Scarpa and

145 Thiene 2005; Colombo et al. 2009). RPL approaches might not reveal the existence of classes

146 since they are constrained by the assumed distribution across individuals, potentially hiding

147 discrete groups. Model fit criterion measures were calculated for all models to assess their

148 suitability to see which approach was most supported.

149 The utility (U) of a good consists of a known or systematic component (V) and a random

150 component $(\varepsilon)$ which is not observable by the researcher. The systematic component of utility

151 can be further decomposed into the specific attributes of the good $(\beta X)$, which in this case is a

152 policy for the establishment of MPAs. Thus, the utility that respondent $n$ derives from a certain

153 MPA alternative $i$ is given by:

$154 U_{\text {in }}=\beta_{\text {in }}+\varepsilon_{\text {in }}$

155 The probability that an individual $n$ will choose MPA alternative $i$ from a set of $J$ alternatives is

156 equal to the probability that the utility derived from $i$ is greater than the utility derived from

157 any other alternative: 
$158 \operatorname{Prob}_{i n}=\operatorname{Prob}\left(U_{i n}>U_{j n}\right) \quad \forall j \in J(2)$

159 Assuming the random term to be independent and identically distributed (IID) according to a

160 type I extreme value distribution, the probability that respondent chooses alternative $i$ in

161 choice occasion $q$ is a standard MNL (McFadden 1974):

$162 L_{n}\left(i, q \mid \beta_{n}\right)=\frac{\exp \left(\beta_{n} X_{i n q}\right)}{\sum_{j}^{J} \exp \left(\beta_{n} X_{j n q}\right)}$

163 If $z_{n t}$ is the respondent's chosen alternative in choice occasion $q$ and $z_{n}=\left(z_{n 1}, z_{n 2}, \ldots, z_{n Q}\right)$ is

164 the sequence of choices in Q choice occasions then the joint probability of the respondent's

165 choices is the product of the standard logits:

$166 \operatorname{Prob}\left(z_{n} \mid \beta_{n}\right)=L\left(z_{n 1}, 1 \mid \beta_{n}\right) \cdots L\left(z_{n Q}, Q \mid \beta_{n}\right)$

167 The term $\beta_{\mathrm{n}}$ is not directly observable, only its density $f(\beta \mid \theta)$ is assumed to be known, where

$168 \theta$ represents the parameters of the distribution. In RPL and LC models the unconditional

169 probability of the respondent's sequence of choices is the integral of equation (4) over all

170 possible values of $\beta_{n}$ determined by the population density of $\beta_{n}$ :

$171 \operatorname{Prob}\left(z_{n} \mid \theta\right)=\int \operatorname{Prob}\left(z_{n} \mid \beta_{n}\right) f\left(\beta_{n} \mid \theta\right) d \beta_{n}$

172 The distribution of $\beta$ will determine the type of model to be used. If $\beta$ is continually distributed

173 it will result in a RPL (McFadden and Train 2000) while if the coefficients are discretely

174 distributed and class membership is homogeneous it results on a LCM, where $\beta$ takes values for 175 each class.

176 The log-likelihoods for both specifications are determined by: 
$177 L(\theta)=\sum_{n}^{N} \ln \operatorname{Prob}\left(z_{n}\right)$

178 Since the choice probability in the RPL does not have a closed form the expression has to be 179 approximated using simulation (Train 2009). Repeated draws of $\beta$ are taken from its density

$180 f(\beta \mid \theta)$. For each draw, the product of logits is calculated and the results are averaged across

181 draws. In this study Halton intelligent draws have been used for the simulation since they have

182 been found to provide greater accuracy than independent random draws in the estimation of

183 RPL models (Train 2009).

$184 L_{R P L}(\theta)=\sum_{n=1}^{N} \ln \left[\frac{1}{D} \operatorname{Prob}\left(z_{n} \mid \beta^{d}\right)\right]$

185 where $D$ is the number of draws and $\beta^{d}$ is the $d^{\text {th }}$ draw. For a LCM with C latent classes, the log-

186 likelihood function is given by:

$187 L_{L C M}(\theta)=\sum_{n}^{N} \ln \left[\sum_{c=1}^{C} \operatorname{Prob}(c) \operatorname{Prob}\left(z_{n} \mid \beta_{c}\right)\right]$

188 where Prob(c) has a MNL form and is the probability of respondent $n$ belonging to class $c$ and $\beta_{c}$ 189 represents a vector of class specific coefficients.

190 Welfare estimates can be derived from the models, they are calculated in the form of

191 willingness to pay (WTP) using the formula:

$192 W T P=\frac{\beta_{a}}{\beta_{c}}$

193 where $\beta_{a}$ is the coefficient of the attribute of interest and $\beta_{c}$ is the negative of the coefficient of 194 the monetary variable. 


\subsection{Area of study}

196 The study focused around the coastal waters of Wales (UK) (Fig. 1), prior to the initiation of

197 formal Government consultation in late 2009. Here, we define Welsh coastal waters as those

198 within the $12 \mathrm{~nm}$ territorial limit. In $2009,32 \%$ of Welsh territorial waters were protected under

199 a range of European and UK designations (Marine Nature Reserve, Special Area of

200 Conservation, Special Protection Area and Site of Special Scientific Interest). However, existing

201 designations were limited in terms of the species, habitats or areas that were afforded

202 protection and also the level of protection these different designations offered. At the time of

203 writing, none of the designated areas were fully protected from human activities.

204 In the UK, the Marine and Coastal Access Act 2009 (DEFRA 2009) provided the legislative

205 powers necessary for the implementation of Marine Conservation Zones (MCZs). Back in 2009

206 in Wales, the MCZ designation was to be primarily used to establish Highly Protected Marine

207 Reserves (HPMRs), these are sites that are generally protected from extraction and deposition

208 of living and non-living resources, and all other damaging or disturbing activities. The aim to

209 establish HPMRs was to complement the existing network of protected areas, resulting in a

210 network of MPAs with varying levels of protection.

211 In 2014, the first MCZ in Welsh waters was established around the island of Skomer and the

212 Marloes Peninsula in Pembrokeshire (NRW 2015). Before 2014 the area had been Wales' only

213 Marine Nature Reserve (MNR) for 24 years. However, Skomer MCZ retained a similar level of

214 protection as when it was a MNR and the HPMR status was not enforced. At the time of writing

215 no area of the Welsh coast was highly protected. 


\subsection{Study design}

217 The first step in any DCE is to define the good to be valued in terms of its attributes and levels.

218 This study focused on those aspects of MPA network design that were most likely to have an

219 impact on society. Initially, the attributes considered for the DCE were the location, total size of

220 the network, level of protection, proportion of areas with different levels of protection and the

221 price associated to the enforcement of protective measures. A focus group was carried out with

22215 randomly sampled members of the general public to define the final list of attributes to be

223 included in the survey. During the meeting the list of attributes, possible associated levels and

224 alternative formats of the DCE survey were discussed. The focus-group exercise revealed that

225 the full set of attributes was too complex to enable respondents to make meaningful trade-offs

226 during the DCEs. The final set of attributes was reduced to include only size, level of protection

227 and cost.

228 The first attribute included in the DCE was the size of the network of MPAs. To define the levels

229 for this attribute, the situation in Wales in 2009 was taken as the baseline. In 2009, 32\% of

230 territorial waters were protected under different EU designations with different levels of

231 protection. According to the statutory Governmental conservation advisory body (Natural

232 Resources Wales), it was unlikely that the area of the new network of MPAs would exceed that

233 of the existing protected areas. Thus, the highest level for the size attribute was set to $30 \%$ of

234 Welsh territorial waters (equivalent to $4,826 \mathrm{~km}^{2}$ ), $20 \%$ and $10 \%$ were chosen as the alternate

235 levels. 
236 The second attribute in the DCE was the type of protection for the MPA network. In this study

237 four levels of protection were selected as a representation of the most common management

238 alternatives in MPAs: (1) no take zones in which no activities were allowed, (2) areas in which

239 only scientific research and educational activities were allowed, (3) non-extractive recreational

240 activities allowed (e.g. scuba-diving, sailing, kayaking) and (4) recreational and commercial

241 fishing using non-damaging equipment to the sea floor allowed.

242 The third attribute included in the DCE was a monetary one, which is required to estimate

243 welfare changes of respondents. The range chosen for the monetary attribute and the payment

244 vehicle were determined during the focus group. The final set of selected attributes, their levels

245 and definition are reported in Table 1.

246 Table 1, about here

247 The final questionnaire contained information on the relevance of the marine environment to

248 society from an economic, cultural and ecological perspective, general information on MPAs,

249 their associated possible outcomes and costs and design issues, and information on the current

250 situation and future plans for Wales. The DCE tasks were located after the general information

251 sections in the questionnaire. In addition to the DCE tasks, information was collected on

252 societal views and attitudes towards MPAs and the environment. Demographic data were

253 collected in order to assess the representativeness of the sample. Average questionnaire

254 completion time was 15 minutes. A copy of the questionnaire is available through the

255 Supplementary Information (SI 1). 


\subsection{Experimental design and data collection}

257 SPSS Orthoplan was used to generate a $\left(3^{1} \times 4^{1} \times 5^{1}\right)$ fractional factorial experimental design,

258 which created 25 choice options (SPSS, 2008). A blocking procedure was used to assign the

259 options to five bundles of five choice sets, thus five versions of the choice experiments were

260 produced. Each version contained a different combination of five DCE tasks and each choice

261 task consisted of three alternatives (A, B and Current situation in Wales, Table 2).

262 Data were collected between May-July 2008 using self-completion questionnaires.

263 Questionnaires were administered to consenting passengers on several train routes covering

264 the entire area of Wales. Bangor University research ethics procedures were followed and

265 informed verbal consent obtained from all participants. Since the completion time of the

266 questionnaire was high and required the full attention of the respondent it was felt that trains

267 would offer a receptive audience willing to participate in the study. In the UK, trains are widely

268 used by a cross section of society including business people, students, retired people and

269 families. Any potential bias that occurred as a consequence of sampling on trains could be

270 assessed through the socio-demographic data collected in the questionnaires (Table 3).

271 Although the chosen survey methodology allowed reaching a broad survey sample, it might

272 have under or over-sampled certain sectors of the population. The problem of sampling hard to

273 reach groups, however, is present in most surveys modes, such as Internet, mail or telephone

274 interviews.

275 Table 2, about here. 
276 Two consecutive pilot phases were conducted on a total of seventy-three respondents prior to

277 the final administration of the survey. Minor corrections to the questionnaires were

278 implemented after the pilots. As the structure of the DCEs tasks did not change during the pilot

279 phases, all pilot questionnaires were included in the final DCE analysis.

280 A total of 448 people were approached to take part in the study of which 78 declined to

281 participate. Of the 368 questionnaires handed out, 14 did not fully complete the DCE section,

282 leaving a total sample of 354 respondents. Each version of the DCE tasks was allocated

283 approximately 71 times.

284 Table 3, about here.

285

286

287

2.5 Model specification

288

Since the interest of the present study was to test for the existence of discrete classes of

289

preference for MPA management within society, we apply LC and RPL models and compare

290

their support. MNL was estimated as a representation of the average preference of the sample

291

since it assumes that preferences are constant across respondents. Models in the study were

292

estimated using mlogit and gmnl R packages (Sarrias and Daziano 2017; Croissant 2018). CE

293

models were designed under the assumption that the observable utility function would follow a

294 strictly additive form. Models were specified so that the probability of selecting a particular

295 MPA configuration scenario was a function of the attributes of that scenario and a constant, 
296 which was specified to equal 1 when either alternative A or B was selected, and 0 when the

297 current situation scenario was selected. Attributes size and cost were treated as continuous

298 variables while effects-coding (Hensher et al. 2007) was used for the allowed uses attribute. A

299 protected network covering $30 \%$ of territorial waters (i.e. Size 30 ) and the permission of

300 recreational uses within the protected areas were used as a baseline in the models for

301 comparative purposes as this combination is what most closely reflects the current situation.

302 Socio-demographic and attitudinal variables were included in the models. An "Environmental

303 consciousness" factor was calculated according to the responses given for a set of questions

304 presented in Table 4. Factor values ranged from 1 to 4, 1 indicating higher degree of

305 environmental consciousness.

306 Table 4, about here.

307 3. RESULTS

308 Sample characteristics

309 A total of 354 respondents completed the questionnaire. To assess the representativeness of

310 the sample, socio-demographic characteristics were compared against Welsh population

311 means. Gender distribution, median age range, household size and average annual income per

312 capita, reflected the distribution in the population (Table 3). However, the proportion of people

313 holding higher education degrees was more than double in the sample than in the population.

314 Conversely, the number of children per household in the sample was lower than in the

315 population. 


\subsection{Public attitudes towards marine conservation}

317 Results from the attitudinal study revealed that public knowledge regarding MPAs was low. On

318 a scale of 1 to 4 ( 1 = "Never heard of MPAs" and $4=$ "I consider I've got a good knowledge of

319 MPAs") $79 \%$ of respondents chose either options 1 or 2.

320 Despite the lack of knowledge on marine protected areas, the questionnaire showed that the

321 general public had a positive and supportive attitude towards marine reserves. Over $66 \%$ of

322 respondents thought that current levels of protection of the sea were insufficient and the vast

323 majority (90\% of the sample) liked knowing that certain areas of the sea were fully protected,

324 and agreed with the principle of protection of the Welsh marine environment even if they

325 might never make use of it. Most respondents (75\%) agreed that MPAs can provide a good

326 balance between conservation and human activities and a high proportion (86\%) thought that

327 there are conservation benefits related to protected areas.

328 Half of the study participants (50\%) believed that the benefits associated with the

329 establishment of protected areas would most likely be greater than its costs. However, in

330 general, it was considered that those affected by the establishment of MPAs should receive

331 compensation for any financial losses (76\%) and that paying higher prices for marine-related

332 products or services was a suitable option in order to facilitate the preservation of areas of the

333 sea around Wales (63\%). Public opinion was equally divided regarding the proposition that no-

334 one should be restricted from using the sea. Half of respondents (50\%) considered that there

335 was no need to restrict uses that do not cause damage to the seafloor, this percentage however

336 dropped to $38 \%$ when the specific use under consideration was fishing. 
3373.2 Determinants of marine protection contribution and latent class preferences

338 The majority of respondents were able to make a choice between the three alternatives offered

339 in the DCE and only $2 \%$ of the sample did not complete the total number of choice tasks. About

$34076 \%$ of respondents were completely, mostly or somewhat certain of the choices they made.

341 One of the two MPA alternatives was chosen $69 \%$ of the times and there is evidence that

342 respondents compared the alternatives, as in $84 \%$ of the cases respondents varied their choice

343 across the five choice tasks. Only $3 \%$ of the sample consistently chose either alternative A or B.

344 Approximately $13 \%$ of respondents who selected the current situation constantly across the

345 tasks were identified as protesters based on their selection of the "I support the conservation of

346 the marine environment but object to having to pay for that" statement. Respondents identified

347 as protesters were excluded from the models as protest responses are inconsistent with the

348 random utility theory framework. Respondents who did not complete all the relevant

349 information sections for the model were also excluded. Models were performed with the

350 remaining 255 respondents. As each respondent undertook five choice tasks, models were run

351 using a total of 1275 observations.

352 3.2.1. Latent Class segmentation

353 Model fit criterion measures, the Akaike (AIC) and the Bayesian Information Criteria (BIC) were

354 estimated for the RPL and LC models with 2 to 5 classes to ascertain their suitability (Scarpa and

355 Thiene 2005). Model fit criterion measures indicated that LC models with 2 to 5 classes

356 presented a better fit than the RPL model. For LC models with increasing number of classes the

357 log likelihood was improved. AIC decreased with increasing number of classes and BIC was at its 
358 minimum for the 2-class model (Table 5). No unequivocal decision could be made on the

359 number of classes. Since the greatest improvement in both log-likelihood and AIC was observed

360 when moving from the 2-class to the 3-class model and to facilitate the interpretation of the

361 results by keeping the number of classes to the minimum, the 3-class model was chosen.

362

363 Table 5, about here

364

365

\subsubsection{The Multinomial logit model (MNL)}

366 Results from the MNL model (Table 6), representing the average preference of the sample,

367 reflect a significant decrease in utility in the reduction of the area of the MPAs from 30 to $10 \%$

368 of Welsh territorial waters, indicated by the negative sign of the WTP (-f23). In terms of the 369 uses allowed within the boundaries of the MPA, the coefficients for HPMR and MPAs where

370 only research activities would be allowed were significant and negative, indicating an

371 opposition for MPAs with these characteristics (- $£ 54$ for HPMRs and $-£ 14$ for MPAs restricted to

372 research). The positive sign of the constant shows a preference for MPAs where recreation is

373 allowed. The coefficient for fishing activities within the boundaries of the MPAs was not

374 significant, denoting an indifference towards the permission of these activities.

375 Table 6, about here

376

377

378 3.2.3. The Latent class model (LCM) 
379 Results for the 3-class LCM are given in Table 6, where the upper part displays the utility

380 coefficients for MPAs attributes and the lower part reports class membership coefficients.

381 Membership coefficients for Class 1 were normalized to zero in order to identify the remaining

382 coefficients and all other coefficients were interpreted relative to this normalized class.

383 The relative size of each class was estimated and each respondent assigned a probability for

384 belonging to each of the three classes. Class membership was determined by the highest

385 probability score. Approximately, $28 \%$ of respondents were identified as members of Class 1 ,

$38634 \%$ as members of Class 2 and $38 \%$ as members of Class 3.

387 Coefficients for the different classes suggest that preferences among classes differed

388 substantially. Costs coefficients were significant for all classes. Members of Class 1 opposed to a 389 reduction in size of the MPA network down to $10 \%$ of territorial waters (WTP $=-£ 43$ ) or to $20 \%$

390 (-£35). Class 1 members did not favor HPMRs $(-£ 94)$ or MPAs were only research related

391 activities were allowed (-£45). The positive sign of the constant indicates a preference for MPAs

392 where recreational activities were permitted. Similarly, they were willing to pay (f23) in order

393 to allow fishing activities within the boundaries of the MPA network. Members of Class 2 were

394 willing to pay (f13) for smaller MPAs which would cover $20 \%$ of territorial waters and were

395 indifferent towards a reduction down to $10 \%$ of territorial waters. They opposed HPMRs (-£25)

396 and MPAs where only research would be allowed (-f15). Recreational activities and fishing

397 ( $f 12$ ) were supported. Members of Class 3 were indifferent towards a reduction in the MPA

398 network down to $20 \%$ but opposed a further reduction to $10 \%$ in the network area (-f91). They

399 were not in favor of HPMRs $(-£ 149)$ but were indifferent towards MPAs where only research 
400 would be allowed. They were in favor of MPAs where recreational activities would be allowed

401 but not of MPAs where fishing could take place $(-£ 113)$. The level of education, income per

402 capita and the level of environmental consciousness showed significant effects on class

403 membership (Table 6). Profiles for the different classes were calculated on the basis of class

404 membership coefficients (Table 7). Members of Class 3 (i.e. against fishing) were characterized

405 by a higher degree of environmental consciousness (i.e. lower Environmental Factor value, EFV

$406=1.5)$, had the highest income per capita $(£ 18,945)$ and the greatest proportion of members

407 with higher education degrees (80\%). Class 3 also showed the greatest proportion of members

408 living within 10 miles of the coast (56\%) and undertaking some type of water related activities

409 (67\%) in comparison to Classes 1 and 2. The proportion of Class 3 members who considered

410 they had good MPA knowledge was also higher (36\%). Members of Class 1 (i.e. bigger MPAs

411 where fishing would be allowed) showed the lowest degree of environmental consciousness

412 (i.e. highest EFV, 2.2), lowest proportion of members with high self-assessed MPA knowledge

$413(15 \%)$ and income per capita $(£ 16,740)$; the proportion of members with higher education

414 degrees (65\%) was in between Classes 2 and 3. Class 2 was characterized by the lowest

415 proportion of people living within 10 miles of the coast (38\%), of people undertaking water

416 activities (47\%), lowest proportion of people with higher education degrees (55\%) and lowest

417 income per capita $(£ 16,447)$. They presented midrange values for MPA knowledge $(21 \%)$ and

418 environmental consciousness (1.9).

419 Table 7, about here.

420 4. DISCUSSION 
421 The main focus of this study was to test the existence of preference heterogeneity classes in

422 society for different types and levels of coastal protection in the form of MPAs in a temperate

423 area. The study provides evidence that the general public supports the establishment of an

424 enhanced network of MPAs in Welsh waters, however it also shows that societal preferences

425 for coastal MPAs are not homogeneous and that different and defined opinion groups exist.

426 This is in agreement with findings from a similar study carried out in the Northeast United

427 States in which three groups with different preferences for MPAs were identified (Wallmo and

428 Edwards, 2008), however not such evidence exists for European waters. Studies with a focus on

429 Europe have either not assessed preference heterogeneity (Wattage et al. 2011) or have done

430 it on an individual basis through the use of Conditional and Random Parametres Logit models

431 (McVittie and Moran 2010; Börger et al. 2014; Jobstvogt et al. 2014a). Studies that have

432 assessed societal heterogeneity on a class level have done it for marine offshore areas

433 (Kermagoret et al. 2016; Börger and Hattam 2017) but no studies have so far focused on the

434 coastal zone. In the following discussion we discuss the validity of the elicited values and the

435 utility of the results for the design of marine management plans.

436 Validity of the DCE values

437 Arguably, the high level of low MPA self-rated knowledge amongst respondents could have

438 hindered the validity of the values elicited from the DCE, since generally DCE encompasses

439 attributes that respondents are familiar with. However, there is evidence that unfamiliarity with

440 particular environmental aspects should not preclude the application of DCE (Barkmann et al.

441 2008) since respondents have been shown capable of learning about unfamiliar aspects during 
442 a DCE experiment and to make choices based on their own moral values (Christie et al. 2006;

443 Kenter et al. 2011). Here, this is supported by the high levels of self-assessed choice certainty

444 and further sustained by the reasonable manner in which certain respondents' characteristics

445 predicted particular choices. As an example, the higher likelihood of a respondent with higher

446 levels of environmental consciousness to prefer MPAs where fishing activities likely to damage

447 the seafloor were banned, shows that a greater concern for the environment is translated into

448 more restrictive management measures. High levels of unfamiliarity with the marine

449 environment have been found in other DCE studies (Börger et al. 2014; Jobstvogt et al. 2014a).

450 However, the focus of these studies was on deep-sea and off-shore areas which, since they are

451 spatially removed from the majority of society, might feel more remote and unfamiliar than

452 coastal areas. Despite this unfamiliarity, valuation studies are important in highlighting the

453 potential economic values held by the average citizen, which are generally absent from

454 economic assessments (Hanley et al. 2014).

455 The DCE analysis points towards a division of society in classes according to their preferences

456 for MPAs design and management. However, the exploration of socio-demographic data

457 revealed the study sample not to be representative of the Welsh population. Therefore, while

458 the outcome of this study is suitable to be used as a guiding and exploratory tool to achieve

459 MPA designs with higher society acceptance, it should not be used as part of full cost benefit

460 analysis or benefit transfer exercises, as the elicited DCE values are not based on a

461 representative sample.

462 Implications for Coastal Management 
463 Outcomes from studies like the one presented here can be used to shape the development and

464 design of MPA networks on coastal waters and maximize the acceptance and compliance of the 465 associated management restrictions. Results suggest the existence of three distinct classes with 466 different sets of preferences regarding the implementation of MPAs. All classes were in favour 467 of MPAs and were not supportive of the idea of MPAs as HPMRs where no activities could be 468 carried out within their boundaries. Instead, all three classes supported those MPAs where non469 damaging recreational activities were allowed. These results align with the concerns expressed 470 by the Welsh public during the public consultation carried out in 2012 on the proposal of highly 471 protected sites around the Welsh coast. Strong opinions were held both for and against the

472 proposed high level of protection. Many were in favour of having such sites but coastal 473 communities and business were concerned about unacceptable socio-economic impacts with 474 little evidence of the benefits (Welsh Government 2013). In addition, it was generally 475 considered unnecessary to have an indiscriminate approach with a high level of protection 476 regardless of whether activities would have an impact on ecological features. In 2014 , the 477 Welsh Government established the first MCZ where the HPMR status was finally not adopted.

478 The main differences between classes arise regarding the size of the network and the 479 permission of fishing activities within their boundaries. We find that two currents of opinion 480 exists, those who are in favour of particular activities within the MPAs (fishing: Class 1 \& Class 4812 2) and those who oppose (fishing: Class 3). In terms of the area covered by the MPA network, 482 there was general support for a network that would cover $30 \%$ of territorial waters, Class 2 also 483 showed support for $20 \%$ of territorial waters while Class 1 was opposed to that idea. In 484 summary, Class 1 favored bigger MPAs where all the activities considered in this study would be 
485 allowed and supported fishing to a greater extend than Class 2, Class 2 was in support of both

486 bigger and medium sized MPAs where recreation and fishing would be allowed and Class 3

487 favored bigger MPAs where recreation but no fishing would be allowed.

488 In accordance with other DCE studies (McVittie and Moran 2010; Wattage et al. 2011; Börger et 489 al. 2014; Jobstvogt et al. 2014b, a; Kermagoret et al. 2016; Börger and Hattam 2017) our results 490 indicate that the general public is willing to bear the additional economic cost associated with 491 the implementation of MPAs. However, the comparison of our study, which has solely focused 492 on coastal MPAs, with others which have included inshore and offshore MPA areas, shows 493 differences between society's preferences for management strategies adopted in exclusively 494 coastal MPAs and those that include inshore and offshore areas. As an example, McVittie and 495 Moran (2010) showed a WTP ranging from - $f 17$ to $f 17$ for highly restrictive measures in a 496 network of MPAs that include both inshore and offshore areas while results from our study 497 indicate a much stronger opposition to HPMRs located in coastal waters $(-£ 25$ to $-f 149)$. This 498 highlights the importance of eliciting separate value estimates for coastal and offshore areas, as 499 it would be incorrect to extrapolate values estimated for offshore areas to coastal zones on 500 benefit transfer exercises. It also serves as an indication that people are capable of making 501 distinctions between the associated society's burden in terms of restrictions between coastal 502 and offshore areas, since the intensity of use of coastal areas by different sectors of society is 503 much greater than for offshore areas, as the latter are generally inaccessible for the majority of 504 people. 
505 Arguably, the design of the DCE in terms of the restriction levels associated with the network of

506 MPAs could have better reflected reality by incorporating zonation within the MPA network.

507 However, the focus groups carried out as part of this study revealed that the cognitive burden

508 imposed by an additional MPA zonation attribute was too great and the design too complex for

509 respondents to make meaningful trade-offs during the DCE. Results indicate that the great

510 majority of the public was not supportive of the idea of MPAs as HPMRs. However, it is possible

511 that the level of support for HPMRs would have increased if the DCE had offered respondents

512 the option of MPAs encompassing areas with a range of different protection and restriction

513 levels. This is supported by the fact that the majority of respondents in the study (90\%)

514 indicated that they "like knowing that certain areas of the sea are fully protected" thus,

515 showing their support for areas where no activities are allowed and biodiversity is fully

516 protected. The combination of the LC DCE and the questionnaire results provides useful

517 information for coastal resource managers as it allows to infer that HPMRs combined with

518 adjacent areas with differing levels of user-access, particularly areas where non-damaging

519 recreational activities would be allowed, would appear to be the type of MPA design that would

520 receive the greatest public support, while also ensuring effective conservation. This conclusion

521 is in line with results from a survey carried out among users of MPAs in southern Europe that

522 showed a strong preference for having MPAs with different use zonation, including areas

523 designated for restricted fishing, non-damaging recreational activities and the full protection of

524 species and ecosystems (Mangi and Austen, 2008). This approach enables decision-makers to

525 evaluate the preferences of those classes with a higher number of members from two

526 complementary angles. On the one hand, the combination of attribute levels that shows the 
527 greatest societal support can be identified and pursued, if the MPA design is in line with 528 conservation objectives. In our study, there is indication that MPAs where fishing activities

529 likely to produce disturbance to the seafloor would be banned but recreation would still be

530 allowed, would receive the greatest level of support. On the other hand, it allows for the

531 identification of large groups that might not be willing to engage in imposed restrictions, which

532 would make management and enforcement more difficult (Ban et al. 2013). In our study, we

533 have been able to identify that all classes object to the concept of highly restrictive MPAs.

534 Consequently, it would not be advisable for managers to pursue the design of MPAs as

535 exclusively no-take zones, where no type of activity would be allowed. Additionally, through LC

536 analysis it is possible to establish a relation between preferences for particular bundles of

537 attributes and respondents characteristics. Here, we find that those respondents in favor of

538 more restrictive MPAs, where fishing was not allowed, have an overall higher environmental

539 consciousness and posses greater MPA related knowledge. These indications provide coastal

540 resource managers with tools to work towards an increased support for MPAs where fishing

541 might not be allowed through environmental and awareness education campaigns. The

542 integration of environmental education as part of MPA management (Zorrilla-Pujana and Rossi

5432014 ) is a necessary element in achieving sustainable management, as access to balanced

544 environmental information provides resource users with a wider picture of environmental and

545 societal benefits related to conservation, becoming more willing to accept trade-offs (Ruiz-Frau

546 et al. 2018).

547 Moreover, these types of approaches provide an opportunity for coastal managers to propose

548 different management measures since society shows an array of divergent interests. Following 
549 preference indications, different types of protected areas can be implemented on different

550 coastal areas accompanied by the assessment of societal post-implementation support and

551 compliance to help in the identification of those MPA design combinations potentially most

552 likely to succeed.

553 5. CONCLUSIONS

554 The attitudes and preferences of resource users of MPAs are a key issue for the management of

555 protected areas (Jones, 2008). It has been widely acknowledged that for the management of

556 MPAs to be successful and to ensure compliance it is necessary that users have positive

557 attitudes towards MPAs and their associated regulations (White et al., 2000; Himes, 2007).

558 Previous studies have investigated the design of MPAs considering influential stakeholder

559 groups preferences such as fishermen (Richardson et al., 2006). Studies which have assessed

560 societal preferences for temperate MPAs have mostly done it for deep-sea and off-shore areas.

561 However, little information has been gathered on societal preferences for MPAs in coastal

562 areas adopting a segmented preference approach. This study shows a general support for the

563 protection of the marine environment in the form of MPAs, however it also shows that there

564 are distinct groups with different preferences for the management of MPAs. We conclude that

565 including this preference heterogeneity in the design of MPA networks in the form of zonation

566 and inclusion of areas which allow recreation but not fishing should be preferred in conjunction

567 with targeted environmental and awareness education campaigns.

568 REFERENCES

569 Balmford A, Gravestock P, Hockley N, McClean CJ, Roberts CM. 2004. The worldwide costs of 

States of America 101:9694-9697. DOI: 10.1073/pnas.0403239101 ER.

572 Ban NC, Mills M, Tam J, Hicks CC, Klain S, StoeckI N, Bottrill MC, Levine J, Pressey RL, Satterfield

573 T, Chan KMA. 2013. A social-ecological approach to conservation planning: Embedding 574 social considerations. Frontiers in Ecology and the Environment 11:194-202. DOI:

575 10.1890/110205.

576

577

578

579

580

581

582

583

584

585

586

587

588

589

Barkmann J, Glenk K, Keil A, Leemhuis C, Dietrich N, Gerold G, Marggraf R. 2008. Confronting unfamiliarity with ecosystem functions: The case for an ecosystem service approach to environmental valuation with stated preference methods. Ecological Economics 65:48-62.

Batel A, Basta J, Mackelworth P. 2014. Valuing visitor willingness to pay for marine conservation - The case of the proposed Cres-Lošinj Marine Protected Area, Croatia. Ocean \& Coastal Management 95:72-80. DOI: 10.1016/J.OCECOAMAN.2014.03.025.

Blyth-Skyrme RE, Kaiser MJ, Hiddink JG, Edwards-Jones G, Hart PJB. 2006. Conservation benefits of temperate marine protected areas: Variation among fish species. Conservation Biology 20:811-820. DOI: 10.1111/j.1523-1739.2006.00345.x.

Börger T, Hattam C. 2017. Motivations matter: Behavioural determinants of preferences for remote and unfamiliar environmental goods. Ecological Economics 131:64-74. DOI: 10.1016/j.ecolecon.2016.08.021.

Börger T, Hattam C, Burdon D, Atkins JP, Austen MC. 2014. Valuing conservation benefits of an 
offshore marine protected area. Ecological Economics 108:229-241. DOI:

591 10.1016/j.ecolecon.2014.10.006.

592

593

594

595

596

597

598

599

600

601

602

603

604

605

606

607

608

Boxall PC, Adamowicz WL. 2002. Understanding heterogeneous preferences in random utility models: A latent class approach. Environmental and Resource Economics 23:421-446. DOI:

10.1023/A:1021351721619.

Boxall PC, Adamowicz WL, Olar M, West GE, Cantin G. 2012. Analysis of the economic benefits associated with the recovery of threatened marine mammal species in the Canadian St. Lawrence Estuary. Marine Policy 36:189-197. DOI: 10.1016/J.MARPOL.2011.05.003.

Caveen AJ, Gray TS, Stead SM, Polunin NVC. 2013. MPA policy: What lies behind the science? Marine Policy 37:3-10. DOI: 10.1016/J.MARPOL.2012.04.005.

Caveen A, Polunin N, Gray T, Stead SM. 2015. The Controversy over Marine Protected Areas. Cham: Springer International Publishing. DOI: 10.1007/978-3-319-10957-2.

CBD. 2008. Conference of the Parties of the Convention on Biological Biodiversity (COP9). Decision IX/20: marine and coastal biodiversity.

Christie P, Bennett NJ, Gray NJ, 'Aulani Wilhelm T, Lewis N, Parks J, Ban NC, Gruby RL, Gordon L, Day J, Taei S, Friedlander AM. 2017. Why people matter in ocean governance: Incorporating human dimensions into large-scale marine protected areas. Marine Policy 84:273-284. DOI: 10.1016/j.marpol.2017.08.002. 

biodiversity. Ecological Economics 58:304-317.

610 Colombo S, Hanley N, Louviere J. 2009. Modeling preference heterogeneity in stated choice 611 data: an analysis for public goods generated by agriculture. Agricultural Economics 40:307612 322. DOI: 10.1111/j.1574-0862.2009.00377.x.

613 Costanza R, de Groot R, Sutton P, van der Ploeg S, Anderson SJ, Kubiszewski I, Farber S, Turner

614 RK. 2014. Changes in the global value of ecosystem services. Global Environmental Change 615 26:152-158. DOI: http://dx.doi.org/10.1016/j.gloenvcha.2014.04.002.

616 Croissant Y. 2018. mlogit: Multinomial Logit Models. R package version 0.3-0.

617 DEFRA. 2009. Marine and Coastal Access Act.

618 Epstein G, Nenadovic M, Boustany A. 2014. Into the deep blue sea: Commons theory and 619 international governance of Atlantic Bluefin Tuna. International Journal of the Commons $620 \quad 8: 277-303$.

621 EU. 2001. European governance. A White paper. Brussels.

622 Halpern BS. 2003. The impact of marine reserves: Do reserves work and does reserve size 623 matter? Ecological Applications 13:S117-S137.

624 Hanley N, Hynes S, Jobstvogt N, Paterson DM. 2014. Economic valuation of marine and coastal 625 ecosystems : Is it currently fit for purpose ? 2:1-38.

626 Hanley N, Wright RE, Adamowicz V. 1998. Using choice experiments to value the environment - 
627 Design issues, current experience and future prospects. Environmental \& Resource $628 \quad$ Economics 11:413-428.

629 Hausman J. 2012. Contingent Valuation: From Dubious to Hopeless. Journal of Economic 630 Perspectives 26:43-56. DOI: 10.1257/jep.26.4.43.

631 Hausman J, McFadden D. 1984. Specification Tests for the Multinomial Logit Model. $632 \quad$ Econometrica 52:1219-1240.

633 Hensher DA, Rose JM, Greene WH. 2007. Applied choice analysis: a primer. Cambridge: $634 \quad$ University Press.

635 Hilborn R. 2018. Are MPAs effective? ICES Journal of Marine Science 75:1160-1162. DOI: $636 \quad 10.1093 /$ icesjms/fsx068.

637 Jobstvogt N, Hanley N, Hynes S, Kenter J, Witte U. 2014. Twenty thousand sterling under the 638 sea: Estimating the value of protecting deep-sea biodiversity. Ecological Economics 97:10639 19. DOI: http://dx.doi.org/10.1016/j.ecolecon.2013.10.019.

640 Jobstvogt N, Watson V, Kenter JO. 2014. Looking below the surface: The cultural ecosystem 641 service values of UK marine protected areas (MPAs). Ecosystem Services 10:97-110. DOI: $642 \quad$ 10.1016/j.ecoser.2014.09.006.

643 Kaiser MJ. 2005. Are marine protected areas a red herring or fisheries panacea? Canadian 644 Journal of Fisheries and Aquatic Sciences 62:1194-1199. DOI: 10.1139/F05-056 ER.

645 Kenter JO, Hyde T, Christie M, Fazey I. 2011. The importance of deliberation in valuing 
646

647

648

649

650

651

652

653

654

655

656

657

658

659

660

661

662

663

664 ecosystem services in developing countries-Evidence from the Solomon Islands. Global Environmental Change 21:505-521. DOI: 10.1016/j.gloenvcha.2011.01.001.

Kermagoret C, Levrel H, Carlier A, Dachary-Bernard J. 2016. Individual preferences regarding environmental offset and welfare compensation: a choice experiment application to an offshore wind farm project. Ecological Economics 129:230-240. DOI: 10.1016/j.ecolecon.2016.05.017.

Klein CJ, Chan A, Kircher L, Cundiff AJ, Gardner N, Hrovat Y, Scholz A, Kendall BE, Airame S. 2008. Striking a balance between biodiversity conservation and socioeconomic viability in the design of marine protected areas. Conservation Biology 22:691-700.

Lancaster KJ. 1966. A new approach to consumer theory. Journal of political economy 74:132157.

Liquete C, Piroddi C, Drakou EG, Gurney L, Katsanevakis S, Charef A, Egoh B. 2013. Current Status and Future Prospects for the Assessment of Marine and Coastal Ecosystem Services: A Systematic Review. Plos One 8:e67737-e67737. DOI: 10.1371/journal.pone.0067737.

Liu S, Costanza R, Farber S, Troy A. 2010. Valuing ecosystem services Theory, practice, and the need for a transdisciplinary synthesis. Ecological Economics Reviews 1185:54-78.

McFadden D. 1974. Conditional logit analysis of qualitative choice behaviour. In: Zarembka P ed. Frontiers of econometrics. New York: Academic Press, 105-142. 
666 McVittie A, Moran D. 2010. Valuing the non-use benefits of marine conservation zones: An 667 application to the UK Marine Bill. Ecological Economics 70:413-424. DOI:

668 http://dx.doi.org/10.1016/j.ecolecon.2010.09.013.

MEA. 2005. Millennium Ecosystem Assessment. Ecosystems and human well-being: a framework working group for assessment report of the Millennium Ecosystem Assessment.

671 Washington: Island Press.

672 Moore J, Balmford A, Allnutt T, Burgess N. 2004. Integrating costs into conservation planning 673 across Africa. Biological Conservation 117:343-350. DOI: 10.1016/j.biocon.2003.12.013 ER.

674 MSFD. 2008. Marine Strategy Framework Directive. Article 13(4).Directive 2008/56/EC.

675 Mwebaze P, MacLeod A. 2013. Valuing marine parks in a small island developing state: a travel 676 cost analysis in Seychelles. Environment and Development Economics 18:405-426. DOI: $677 \quad 10.1017 /$ S1355770X12000538.

678 NRW. 2015. Skomer Marine Conservation Zone. Marine life in an underwater refuge. Natural $679 \quad$ Resources Wales. areas. 2010. validity of discrete choice experiments in valuing non-market environmental goods. 
684

685

686

687

688

689

690

691

692

693

694

695

696

697

698

699

700

701

702

703

Journal of Environmental Management 183:98-109. DOI:

10.1016/J.JENVMAN.2016.08.032.

Ressurreição A, Gibbons J, Kaiser M, Dentinho TP, Zarzycki T, Bentley C, Austen M, Burdon D, Atkins J, Santos RS, Edwards-Jones G. 2012. Different cultures, different values: The role of cultural variation in public's WTP for marine species conservation. Biological Conservation 145:148-159. DOI: 10.1016/J.BIOCON.2011.10.026.

Roberts CM, Andelman S, Branch G, Bustamante RH, Castilla JC, Dugan J, Halpern BS, Lafferty KD, Leslie H, Lubchenco J, McArdle D, Possingham HP, Ruckelshaus M, Warner RR. 2003. Ecological criteria for evaluating candidate sites for marine reserves. Ecological Applications 13:S199-S214.

Rogers AA. 2013. Public and Expert Preference Divergence: Evidence from a Choice Experiment of Marine Reserves in Australia. Land Economics 89:346-370.

Rolfe J, Windle J. 2012. Distance Decay Functions for Iconic Assets: Assessing National Values to Protect the Health of the Great Barrier Reef in Australia. Environmental and Resource Economics 53:347-365. DOI: 10.1007/s10640-012-9565-3.

Ruiz-Frau A, Kaiser MJ, Edwards-Jones G, Klein CJ, Segan D, Possingham HP. 2015a. Balancing extractive and non-extractive uses in marine conservation plans. Marine Policy 52:11-18. DOI: 10.1016/j.marpol.2014.10.017.

Ruiz-Frau A, Krause T, Marbà N. 2018. The use of sociocultural valuation in sustainable environmental management. Ecosystem Services 29:158-167. DOI: 
705

706

707

708

709

710

711

712

713

714

715

716

717

718

719

720

721

722

Ruiz-Frau A, Possingham HP, Edwards-Jones G, Klein CJ, Segan D, Kaiser MJ. 2015b. A multidisciplinary approach in the design of marine protected areas: Integration of science and stakeholder based methods. Ocean and Coastal Management 103:86-93. DOI: 10.1016/j.ocecoaman.2014.11.012.

Sarrias M, Daziano R. 2017. Multinomial Logit Models with Continuous and Discrete Individual Heterogeneity in R: The gmnl Package. Journal of Statistical Software 79:1-46. DOI: 10.18637/jss.v079.i02.

Scarpa R, Thiene M. 2005. Destination choice models for rock climbing in the Northeastern Alps: A latent-class approach based on intensity of a latent-class approach preferences. Land Economics 81:426-444. DOI: 10.3368/le.81.3.426.

Sorice MG, Oh C-O, Ditton RB. 2009. Managing Scuba Divers to Meet Ecological Goals for Coral Reef Conservation. DOI: 10.1579/0044-7447(2007)36[316:MSDTME]2.0.CO;2.

SPSS Inc. Released 2008. SPSS Statistics for Windows, Version 17.0. Chicago: SPSS Inc

Stefansson G, Rosenberg AA. 2006. Designing marine protected areas for migrating fish stocks. Journal of fish biology 69:66-78. DOI: 10.1111/j.1095-8649.2006.01276.x ER.

Torres C, Hanley N. 2016. Economic valuation of coastal and marine ecosystem services in the 21st century: an overview from a management perspective. DEA WP no.75, Working paper series. Universitat de les Illes Balears 
723 Torres C, Hanley N. 2017. Communicating research on the economic valuation of coastal and

724 marine ecosystem services. Marine Policy 75:99-107. DOI: 10.1016/j.marpol.2016.10.017.

725 Train K. 2009. Discrete choice methods with simulation. Cambridge: Cambridge University Press.

726 Wattage P, Glenn H, Mardle S, Van Rensburg T, Grehan A, Foley N. 2011. Economic value of

727 conserving deep-sea corals in Irish waters: A choice experiment study on marine protected

728 areas. Fisheries Research 107:59-67. DOI: 10.1016/j.fishres.2010.10.007.

729 Welsh Government. 2013. Report of the Task and Finish Team on MCZs in Wales. WG 18753.

$730 \quad$ Crown Copyright 2013. ISBN 978-0-7504-9545-5

731 Zorrilla-Pujana J, Rossi S. 2014. Integrating environmental education in marine protected areas

732 management in Colombia. Ocean and Coastal Management 93:67-75. DOI:

$733 \quad 10.1016 / j .0 c e c o a m a n .2014 .03 .006$. 


\section{Figure 1}

Overview map of the study area

Dashed lines indicate the $12 \mathrm{~nm}$ territorial waters limit, marine Special Conservation Areas (SACS) are shown in blue, green lines indicate the train routes where questionnaires were undertaken 


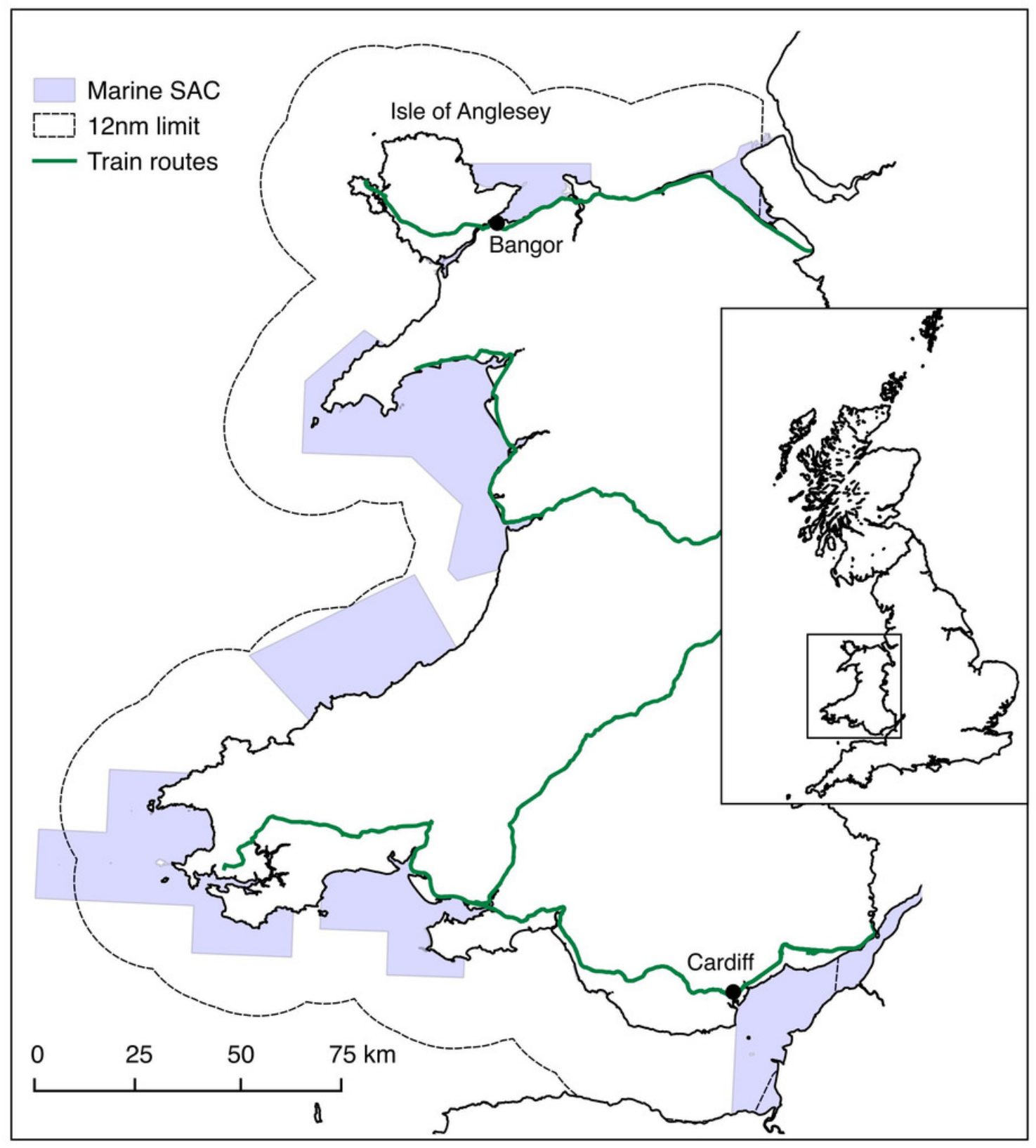




\section{Table 1 (on next page)}

Attributes and levels used in the choice experiment 
1 Table 1. Attributes and levels used in the choice experiment

\begin{tabular}{|c|c|c|}
\hline Attribute & Definition & Levels \\
\hline Network size & Percentage of territorial waters to be protected & $10 \%, 20 \%, 30 \%$ \\
\hline Uses permitted & $\begin{array}{l}\text { Uses permitted within the boundaries of the } \\
\text { network }\end{array}$ & $\begin{array}{l}\text { - All activities prohibited } \\
\text { - Only scientific research and educational } \\
\text { activities } \\
\text { - Non-extractive activities (i.e. sailing, } \\
\text { diving, kayaking, wildlife watching) allowed } \\
\text { - Recreational and commercial fishing using } \\
\text { non-damaging equipment to the sea floor } \\
\text { allowed (previous level included) }\end{array}$ \\
\hline Cost & $\begin{array}{l}\text { Household annual contribution to a neutral } \\
\text { charity. The charity works with the government } \\
\text { to negotiate, monitor and manage the MPAs }\end{array}$ & Payment levels: $£ 5, £ 10, £ 25, £ 50, £ 100$ \\
\hline
\end{tabular}


Table 2 (on next page)

Choice card example 


\begin{tabular}{|c|c|c|c|}
\hline & Option A & Option B & Current Situation \\
\hline $\begin{array}{l}\text { Size of the } \\
\text { network of } \\
\text { MPAs }\end{array}$ & $\begin{array}{c}20 \% \text { of coastal } \\
\text { waters (equivalent } \\
\text { to } 4 \frac{1}{2} \text { times the area } \\
\text { of Anglesey) }\end{array}$ & $\begin{array}{c}30 \% \text { of coastal } \\
\text { waters } \\
\text { (equivalent to } 63 / 4 \\
\text { times the area of } \\
\text { Anglesey) }\end{array}$ & $\begin{array}{c}30 \% \text { of coast as SAC } \\
\text { (equivalent to } 63 / 4 \\
\text { times the area of } \\
\text { Anglesey) }\end{array}$ \\
\hline $\begin{array}{l}\text { Level of } \\
\text { Protection }\end{array}$ & $\begin{array}{l}\text { Only scientific } \\
\text { research and } \\
\text { educational } \\
\text { activities allowed }\end{array}$ & $\begin{array}{l}\text { Non-extractive } \\
\text { activities (i.e. } \\
\text { sailing, diving, } \\
\text { kayaking, wildlife } \\
\text { watching) allowed }\end{array}$ & $\begin{array}{c}\text { Minimum level of } \\
\text { protection } \\
\text { Most activities } \\
\text { including } \\
\text { commercial fishing } \\
\text { allowed }\end{array}$ \\
\hline $\begin{array}{l}\text { Cost to you each } \\
\text { year }\end{array}$ & $£ 25$ & $£ 5$ & $\begin{array}{c}\text { No additional cost to } \\
\text { you }\end{array}$ \\
\hline $\begin{array}{l}\text { Which of the } \\
\text { three options do } \\
\text { you most } \\
\text { prefer? }\end{array}$ & $\begin{array}{c}\text { I prefer Option A } \\
\square\end{array}$ & $\begin{array}{c}\text { I prefer Option B } \\
\square\end{array}$ & $\begin{array}{c}\text { I prefer the Current } \\
\text { Situation } \\
\square\end{array}$ \\
\hline
\end{tabular}

1

2 Table 2. Choice card example 


\section{Table 3(on next page)}

Comparison of respondents' socio-demographic characteristics vs. 2011 census data for Wales (ONS 2012) 
1 Table 3. Comparison of respondents' socio-demographic characteristics vs. 2011 census data for Wales 2 (ONS 2012)

3

\begin{tabular}{|lcc|}
\hline & $\begin{array}{c}\text { Sample } \\
\text { average }\end{array}$ & Census average \\
\hline Gender (\% male) & 49 & 52 \\
Median age range & $45-59$ & $45-59$ \\
University degree \& above (\%) & 63 & 24 \\
Household size & 2.6 & 2.4 \\
Number of children & 0.5 & 1.7 \\
Annual income x capita $(£)$ & 15,248 & 14,129 \\
\hline
\end{tabular}

4 


\section{Table 4 (on next page)}

Environmental statements included in the survey measured on a five-point Likert scale, ranging from "Completely true" to "Not at all true". 
1 Table 4. Environmental statements included in the survey measured on a five-point Likert scale, 2 ranging from "Completely true" to "Not at all true".

Environmental statements
MPAs provide a good way to get the right balance between conservation and activities such as fishing
or shipping
There are conservation benefits related to MPAs
There is no need for MPAs in Wales because the seas around the Welsh coasts are in good health
People who are affected by the creation of MPAs, like fishermen, should receive compensation for any
financial losses derived from the establishment of MPAs
I'm willing to pay higher prices for sea-related products or services to preserve areas of the sea around
Wales
Costs of MPAs will most likely be greater than the benefits obtained from them
MPAs should be large enough to protect every type of organism living in the sea regardless of costs
The sea is a common resource and no one should be restricted from using it
There is no need to restrict uses that don't damage the seafloor in MPAs
Fishing equipment that sits on the seafloor and does not cause damage should be allowed in MPAs
Current levels of protection of the sea are enough
I like knowing that certain areas of the sea are being fully protected

3

4 


\section{Table 5 (on next page)}

Model fit criterion measures for Latent Class models with 2, 3, 4 and 5 classes. 
1 Table 5. Model fit criterion measures for Latent Class models with 2, 3, 4 and 5 classes

\begin{tabular}{lccccc}
\hline & RPL & \multicolumn{4}{c}{ LC - N classes } \\
\cline { 3 - 6 } & & 2 & 3 & 4 & 5 \\
\hline Log likelihood & -1275 & -997 & -958 & -932 & -919 \\
AIC & 2577 & 2031 & 1977 & 1950 & 1947 \\
BIC & 2646 & 2130 & 2137 & 2171 & 2230 \\
\hline
\end{tabular}

2 
Table 6 (on next page)

Parameter estimates for three-class latent class model. Size 30 and recreational uses have been used as a baseline in the models. 
1 Table 6. Parameter estimates for three-class latent class model. Size 30 and recreational uses have been 2 used as a baseline in the models

\begin{tabular}{|c|c|c|c|c|c|c|c|c|c|c|c|c|}
\hline & \multicolumn{3}{|c|}{ MNL } & \multicolumn{9}{|c|}{ Latent Class } \\
\hline & \multirow[b]{2}{*}{ Coef. } & \multirow[b]{2}{*}{ (s.e.) } & \multirow[b]{2}{*}{ WTP } & \multicolumn{3}{|c|}{ Class 1} & \multicolumn{3}{|c|}{ Class 2} & \multicolumn{3}{|c|}{ Class 3} \\
\hline & & & & Coef. & (s.e.) & WTP & Coef. & (s.e.) & WTP & Coef. & (s.e.) & WTP \\
\hline \multicolumn{13}{|c|}{$\begin{array}{l}\text { Utility function } \\
\text { parameters }\end{array}$} \\
\hline Const & 1.70 & $(0.12)^{* *}$ & & 1.36 & $(0.37)^{* * *}$ & & 3.51 & $(0.66)^{* * *}$ & & 4.61 & $(0.68)^{* * *}$ & \\
\hline Size 10 & -0.46 & $(0.09)^{* *}$ & $*-23$ & -1.24 & $(0.30)^{* * *}$ & -43 & 0.91 & $(0.57)$ & & -0.39 & $(0.15)^{* *}$ & -91 \\
\hline Size 20 & -0.14 & $(0.09)$ & & -1.00 & $(0.28)^{* * *}$ & -35 & 1.44 & $(0.54)^{* *}$ & 13 & -0.03 & $(0.14)$ & \\
\hline HPMR $^{a}$ & -1.08 & $(0.12)^{* *}$ & $*-54$ & -2.71 & $(0.49)^{* * *}$ & -94 & -2.80 & $(0.64)^{* * *}$ & -25 & -0.64 & $(0.19)^{* * *}$ & ${ }^{*}-149$ \\
\hline Res & -0.43 & $(0.11)^{* *}$ & ${ }^{*}-14$ & -1.31 & $(0.38)^{* * *}$ & -45 & -1.65 & $(0.61)^{* *}$ & -15 & -0.00 & $(0.18)$ & \\
\hline Fish & 0.17 & $(0.10)$ & & 0.66 & $(0.27)^{* *}$ & 23 & 1.35 & $(0.64)^{*}$ & 12 & -0.48 & $(0.17)^{* *}$ & -113 \\
\hline Cost & -0.02 & $(0.00)^{* *}$ & & -0.03 & $(0.00)^{* * *}$ & & -0.11 & $(0.03)^{* * *}$ & & -0.01 & $(0.0)^{*}$ & \\
\hline \multicolumn{13}{|c|}{ Class membership function } \\
\hline $\mathrm{HE}^{\mathrm{b}}$ & & & & & & & 0.19 & $(0.07)^{* *}$ & & -0.17 & $(0.08)^{*}$ & \\
\hline Acts $^{\mathrm{c}}$ & & & & & & & 0.24 & (0.19) & & -0.19 & $(0.20)$ & \\
\hline $\mathrm{EnvF}^{\mathrm{d}}$ & & & & & & & -1.27 & $(0.21)^{* * *}$ & & -4.14 & $(0.30)^{* * *}$ & \\
\hline Inc $x$ cap & & & & & & & 0.00 & $(0.00)$ & & 0.00 & $(0.00)^{* * *}$ & \\
\hline LC prob & & & & 0.28 & & & 0.34 & & & 0.38 & & \\
\hline Loglike & -1382 & & & -958 & & & & & & & & \\
\hline AIC & 2779 & & & 1977 & & & & & & & & \\
\hline $\mathrm{BIC}$ & 2815 & & & 2137 & & & & & & & & \\
\hline N Resp & 255 & & & 255 & & & & & & & & \\
\hline N Obs & 1275 & & & 1275 & & & & & & & & \\
\hline
\end{tabular}

3

$4 \quad * * * 0.1 \%$ significance level, $* * 1 \%$ significance level, $* 5 \%$ significance level

5 aHPMR: Highly Protected Marine Reserve, bHigher Education, 'Water related activities (marine), dEnvironmental factor, elncome per capita 
Table 7 (on next page)

Respondents' profiles for each latent class. 
1 Table 7. Respondents' profiles for each latent class

2

\begin{tabular}{|llcl|}
\hline & Class 1 & Class 2 & Class 3 \\
\hline Within 10 miles \% & 49 & 38 & 56 \\
Water Activities \% & 48 & 47 & 67 \\
High MPA knowledge \% & 15 & 21 & 36 \\
Environmental Factor & 2.2 & 1.9 & 1.5 \\
Higher Education \% & 65 & 55 & 80 \\
Income x capita (£) & 16,740 & 16,447 & 18,945 \\
Household size & 2.8 & 2.7 & 2.6 \\
Gender \% males & 46 & 42 & 53 \\
\hline
\end{tabular}

3

4 